\title{
Deep etching of glass wafers using sputtered molybdenum masks
}

\author{
Frederik Ceyssens and Robert Puers
}

\author{
KULeuven, dept. ESAT-MICAS, Kasteelpark Arenberg 10, Leuven, \\ Belgium \\ e-mail: fceyssen@esat.kuleuven.be
}

\begin{abstract}
This paper presents a simple low cost technology to fabricate very deep isotropically etched features in glass wafers. A process based on a fast etching glass combined with a stress-optimized molybdenum mask layer and a photoresist was found very suitable for such purposes. The obtained performance, up to $1.2 \mathrm{~mm}$ deep etching, rivals the best existing techniques while being more cost-competitive and using widely available equipment.
\end{abstract}

\section{Introduction}

Of all substrates, glass certainly offers the most attractive resource for the fabrication of optical and fluidic microsystems. The cost of quality glass substrates is at least one order of magnitude lower than for silicon, an obvious advantage, especially in area-hungry applications. The excellent transparency is another welcomed advantage: it simplifies the inspection, facilitates optical detection and eases the integration of waveguides. Furthermore, glasses display a high chemical inertness and are excellent electrical insulators. Many glass applications in micromachining require patterning of the glass substrate.

Due to the formation of nonvolatile compounds, dry etching of glass is a relatively slow process with a typical etch rate of $0.6 \mu \mathrm{m}$ per minute in a recent ICP system [1]. Thus, the system is occupied almost 14 hours to etch through a single $500 \mu \mathrm{m}$ thick wafer. Furthermore, to etch through holes, nickel masks of typically 20 microns thick or more are mandatory. Therefore, when no high aspect ratios are required, isotropic wet etching in a hydrogen fluoride (HF) solution is still the preferred technology for deep etching.

However, finding a mask that withstands a long exposure time to HF is certainly not straightforward and has been the subject of several recent publications (see section 4). Most authors use either evaporated gold layers or CVD deposited silicon or silicon carbide, and Pyrex glass.

The purpose of this work is to obtain a performance similar to the best reported in terms of maximum etch depth and mask undercut, using only low cost materials and processes. The investigation focused on achieving this by the use of a low cost float glass and a masking technique based on a simple sputtered metal mask. Emphasis is put on processing optimization to yield long lasting, pinhole free masking layers. 


\section{Glass types for micromachining}

Four glass types suited for micromachining applications are Pyrex 7740 (Corning Glassworks), D263 (Schott), AF45 (Schott) and pure silica. D263 and AF45 are so-called float glasses, produced by casting a molten mix of oxides on molten tin, on which the mix floats and solidifies. This creates a very even, optically smooth slide of a uniform thickness. Because of its low loss tangent, AF 45 is commonly used as a substrate for RF MEMS. On the other hand, D263 is mostly used for expendable cover glasses in microscopy, and thus produced in mass and relatively cheap. It is available in an alkali-containing D263m and an alkali-free D263t version, having similar optical and etching characteristics. The float glasses are available in a wide range of thicknesses, including very thin plates of only a few tens of microns in thickness. The other glass substrates are produced by cutting, grinding and polishing bulk material and are typically available in thicknesses from $500 \mu \mathrm{m}$ upwards only, and are more expensive.

Whereas the mechanical properties at room temperature are quite similar, the thermal properties of several glass types differ considerably as can be seen in table 1 . The built-in stress of thin films deposited above room temperature on the substrate can therefore differ considerably depending on the type of glass used. Therefore, it is not surprising that the optimal deposition parameters obtained for one type of glass must be adapted when a thin film deposition process is needed for another type of glass. Also, etch rates in HF vary considerably as discussed below.

Table 1: Glass properties. Suppliers' data.

\begin{tabular}{|c|c|c|c|c|}
\hline & Pyrex 7740 & D263t & AF 45 & Fused silica \\
\hline density [g/cc] & 2.23 & 2.51 & 2.72 & 2.18 \\
\hline Young's modulus [GPa] & 62.5 & 72.9 & 66 & 73 \\
\hline Poisson coeff & 0.2 & 0.208 & 0.235 & 0.17 \\
\hline CTE $[p p m / K] 20-200^{\circ} \mathrm{C}$ & 3.25 & 7.2 & 4.5 & 0.7 \\
\hline Strain point $\left[{ }^{\circ} \mathrm{C}\right]^{+}$ & 510 & 529 & 627 & 990 \\
\hline Annealing Point $^{++}$ & 560 & 557 & 663 & 1100 \\
\hline Loss tangent (1MHz) & $5 \cdot 10^{-3}$ & $6.1 \cdot 10^{-3}$ & $9 \cdot 10^{-4}$ & $7.5 \cdot 10^{-4^{*}}$ \\
\hline dielectric constant & 4.1 & 6.7 & 6.2 & 3.78 \\
\hline
\end{tabular}

\section{Glass etching using HF}

\subsection{Introduction}

In this part, etch experiments on blank wafers are described. This enables to draw already some conclusions with respect to process selection.

Hydrogen fluoride (HF) is one of the rare chemicals that can dissolve glass. For this reason it is commonly used in microelectronic processing despite its acute toxicity. Silicon oxide, the main constituent of glasses, reacts with it as follows [2]

$$
6 \mathrm{HF}+\mathrm{SiO}_{2}-->\mathrm{H}_{2} \mathrm{SiF}_{6}+2 \mathrm{H}_{2} \mathrm{O}
$$

Non-silica glasses contain other oxides as well, such as $\mathrm{Al}_{2} \mathrm{O}_{3}, \mathrm{~B}_{2} \mathrm{O}_{3}, \mathrm{MgO}$, and $\mathrm{Na}_{2} \mathrm{O}$. They react with $\mathrm{HF}$ in a similar way. Some fluorides that form as a byproduct of those reactions, such as $\mathrm{CaF}_{2}, \mathrm{MgF}_{2}$ and $\mathrm{AlF}_{3}$, are not soluble in water, however. They may partially redeposit on the substrate, causing a rougher etched surface because of micromasking and a reduced etch rate [3]. A method to circumvent this is adding $\mathrm{HCl}$ to the etch bath [4]. $\mathrm{HCl}$ transforms the non-soluble fluorides into soluble chloride species. The optimal amount of $\mathrm{HCl}$ is about 1 $\mathrm{ml}$ of HCL (37\%) for each $10 \mathrm{ml}$ of $\mathrm{HF}$ (49\%) [5]. Adding this amount of $\mathrm{HCl}$ decreases the etch rate by only $5 \%$. 


\subsection{Experiments}

HF concentration, temperature and the agitation are important parameters for the etch process. In our selected process, a $25 \%$ HF etch bath was selected as a compromise between etch speed, the consumption of chemicals and danger for the operator as concentrated HF produces a significant amount of toxic vapor.

The etch rate on D263t and D263m glass was measured to be $5.2 \mu \mathrm{m} / \mathrm{min}$ at room temperature. The typical Ra roughness after $200 \mu \mathrm{m}$ deep etching is lower than $10 \mathrm{~nm}$ measured using a Dektak stylus profile meter. For Pyrex 7740, the etch rate in the same setup is $1.12 \mu \mathrm{m} / \mathrm{min}$ and similar uniformity and roughness are obtained.

After selecting the etch solution, the type of agitation needs to be decided on. Ultrasonic agitation was tried experimentally, but had to be discarded as it caused severe damage due to mask undercut. Also, it degraded the etch uniformity because of micromasking by redeposited mask debris. Mechanical agitation was no option, because it would require a very high agitation uniformity, since the diffusion-limited reactions are strongly dependent on the supply of fresh reactants [6].

Interestingly, the absence of any agitation produced quite uniform etching: in that case an etch uniformity better than $0.5 \%$ was measured for a $200 \mu \mathrm{m}$ etch on an unstructured D263m glass wafer. This makes the process sufficiently accurate for chemical wafer thinning. The values obtained are for wafers positioned vertically in the etch bath. An important observation in an unagitated etch bath could be made: glass wafers etched in a horizontal position became rough and lost their optical clarity already after several tens of microns of etching. For wafers positioned vertically this was not observed. The effect was observed both for D263 and Pyrex glass. When etching AF45 glass in 25\% HF, a visible crust did form in either case.

A possible explanation for this is the build up of the non soluble species produced by the reactions mentioned above. It appears gravity suffices to prevent build-up of non soluble species on the etched surface. The visible crust formed on the surface of the AF 45 is substantional, and can be explained by its high aluminum oxide content, producing significant quantities of non dissolvable aluminum fluoride.

\subsection{Conclusion}

Because of improved removal of non soluble species, glass wafer thinning in HF should be done with the wafers held vertically without agitation. In that case, a smooth and uniform etch process is obtained. Etch processes using a structured mask such as described in the next section are best conducted with the features facing the bottom of the etch bath.

\section{Masking for deep wet HF etch}

\subsection{Introduction}

Finding a thin film layer or a combination of layers that can resist submergence in HF for the period of time necessary to etch deep features in the substrate is not straightforward. There are many materials that are not attacked by HF in bulk form. However, this does not imply that a thin film of such a material can protect the surface for an indefinite amount of time. Delamination, especially around features in the mask, was often observed in our preliminary experiments as well as in literature. This delamination causes the lateral undercutting etch to proceed faster than the downward etch. Hence, the maximum underetch ratio (UR) of the features, here defined as the ratio between the etch depth and the mask underetch, is often smaller than 1, the maximum achievable with isotropic etching. 
Another failure mechanism is the appearance of pinholes in the mask layer at random locations.

Table 2: Comparison of mask layers, showing maximum attainable depth and underetch ratio (UR).

\begin{tabular}{c|c|c|c|l} 
Description & UR & $\begin{array}{c}\text { Max. depth or } \\
\text { time }\end{array}$ & Ref. & \multicolumn{1}{|c}{ remarks } \\
\hline photoresist & $1 / 5$ & $10-20 \mu \mathrm{m}$ & {$[4][7][8]$} & \\
\hline $\mathrm{Cr}^{*} / \mathrm{Au}(50+400 \mathrm{~nm})$ & $\sim 1$ & $150 \mu \mathrm{m}$ & {$[3][7][9]$} & \\
\hline $\mathrm{Cr} / \mathrm{Au}(50+1200 \mathrm{~nm})$ & $\sim 1 / 1$ & $\begin{array}{c}600 \mu \mathrm{m} \text { or } 45 \\
49 \% \mathrm{HF}\end{array}$ & {$[3]$} & $\begin{array}{l}\text { low stress layer by evaporation, not } \\
\text { sputtering }\end{array}$ \\
\hline $\begin{array}{c}\text { Double } \mathrm{Cr} / \mathrm{Au}(60+400 \mathrm{~nm})+ \\
\text { SPR220-7 resist }\end{array}$ & 0.8 & $300 \mu \mathrm{m}$ & {$[10]$} & \\
\hline $\mathrm{Cr}$ & & $100 \mu \mathrm{m}$ & {$[11]$} & $\begin{array}{l}\text { pinhole formation before etch depth is } \\
\text { reached }\end{array}$ \\
\hline $\mathrm{Cr}+\mathrm{Cu}$ & 0.8 & $100 \mu \mathrm{m}$ & {$[12]$} & \\
\hline poly Si. 500nm & & $400 \mu \mathrm{m}$ & {$[7][13]$} & High deposition temperatures $\left(620^{\circ} \mathrm{C}\right)$ \\
\hline $\mathrm{Amorph}$ Si & 1 & $250 \mu \mathrm{m}$ & {$[12]$} & More acceptable T (PECVD) \\
\hline Anodicly bonded bulk Si & 0.6 & unlimited & {$[14]$} & large underetch, slow and expensive \\
\hline amorph.Si+ resist & 1 & $500 \mu \mathrm{m}$ & {$[7][15]$} & \\
\hline Amorph.Si / SiC/resist & 1 & $1000 \mu \mathrm{m}$ & {$[16]$} & \\
\hline
\end{tabular}

Factors that can indicate the suitability of a certain layer as a mask for HF etching are its hydrophobicity and its built-in stress [5]. A hydrophobic layer is better as the etchant will not penetrate small cracks. Such cracks can for example be formed by the stress in the layer being underetched. To avoid this, a slight compressive stress on the mask layer is preferred over tensile stress. As will become clear in the next paragraph, careful optimization of the deposition parameters for the mask layer will be necessary to achieve this. A final stress category of importance, especially in multilayer coatings, are bending stresses. They can generate mask peeloff if they outclass the adhesion strength.

Furthermore, the morphology of the film is important [17]. As explained in the introduction, sputtering is selected as deposition technique for the mask layers in this work. The morphology of sputtered films depends on the deposition conditions. According to the Thornton zone model [18] that discerns sputtered layers according to the pressure and temperature of sputtering in four categories, dense films are generated by sputtering at relatively low pressure and low temperature compared to the melting temperature of the material $T_{M}\left(T_{\text {sputter }} / T_{M}<0.5\right)$. Porous, low stress layers are generated at higher pressures. Such layers are of no use as an etch mask. The high-temperature regimes are also not considered as the softening temperature of glass is rather low compared to the melting point of the mask layers considered.

In literature (table 2), several process options are already explored. A popular process is the use of relatively thick evaporated gold with a chromium adhesion layer. Etching depths of up to $600 \mu \mathrm{m}$ are reported for this technique [3]. Another route often followed is the use of CVD or PECVD deposited silicon or silicon carbide layers, achieving an etch depth of up to $1 \mathrm{~mm}$ [16].

In the experiments described next, the goal was to find an economically more interesting and widely available technology to obtain deep etched glass, based on low-cost sputtered metal layers. 


\subsection{Preliminary experiments}

Different low-cost mask layers were tested for single-side etching, based on the literature mentioned. Masks that did not really satisfy are briefly mentioned here without going into much detail. The initial substrate used was Pyrex 7740.

Among the tested photoresist masks (S1818, SU-8, SPR220-7), the thick SPR220-7 positive photoresist mask proved to work best on piranha-cleaned, dehydrated and HMDS-sylanated glass. Still, because of the large underetch, it can only be used for shallow etches. Other authors did report depths of 70 microns by using diluted HF and stirring [4], but we could not reproduce their results with any acceptable underetch.

Sputtered copper mask layers (with or without tantalum adhesion layer) proved to be prone to pinhole formation, limiting the use to etch depths of a few tens of $\mu \mathrm{m}$. The same is true for sputtered chromium layers using a standard process.

More success was achieved with a sputtered chromium layer with a hard baked positive S1818 resist on top. Sputtering conditions were optimized to minimize stress. Also, nitric acid was added to the etch bath to lower the $\mathrm{pH}$ for increased uniformity (see section 3), at the same time oxidizing the chromium, making it more resilient against HF attack. This process achieves etch depths of about $250 \mu \mathrm{m}$ though mask opening larger than the etching depth and etches Pyrex glass mirror-smooth. A typical roughness measurement yields $\mathrm{Ra}<10 \mathrm{~nm}$ after a $100 \mu \mathrm{m}$ deep etch, measured by a Dektak stylus profiler. Process paremeters can be found on the left of table 3 .

\subsection{Molybdenum mask-based etch}

After these initial expertiments, several changes were introduced that led to the improved result. First, D263m glass was selected as preferred glass substrate because of its low cost and high etch rate compared to the more widely used Pyrex 7740. Furthermore, its CTE (table 1) is larger than the CTE of molybdenum, $5.35 \mathrm{ppm} /{ }^{\circ} \mathrm{C}$ [19]. This facilitates the introduction of compressive stress in the mask layer during sputtering. The glass was obtained as $300 \mu \mathrm{m}$ thick microscope cover glasses from Menzel Gläser.

Second, a sputtered molybdenum layer fortified with thick SPR220-7 photoresist was selected as mask. Molybdenum was selected because of its good adhesion to both glass and photoresist and its inertness for HF.

Magnetron sputtering parameters were optimized in order to obtain a slight compressive stress. 150W RF power at $13.56 \mathrm{MHz}$ was applied and 3" targets were used. For a range of pressures, the stress in the layer sputtered on the glass wafers was determined by measuring the wafer bending and applying Stoney's equation [20]. The results are shown in figure 1 . The selected pressure for our process is $1.010^{-2}$ mbar, yielding a compressive stress of 33 MPa. In all the following experiments, a one micron thick layer of molybdenum applied by this recipe was used. 


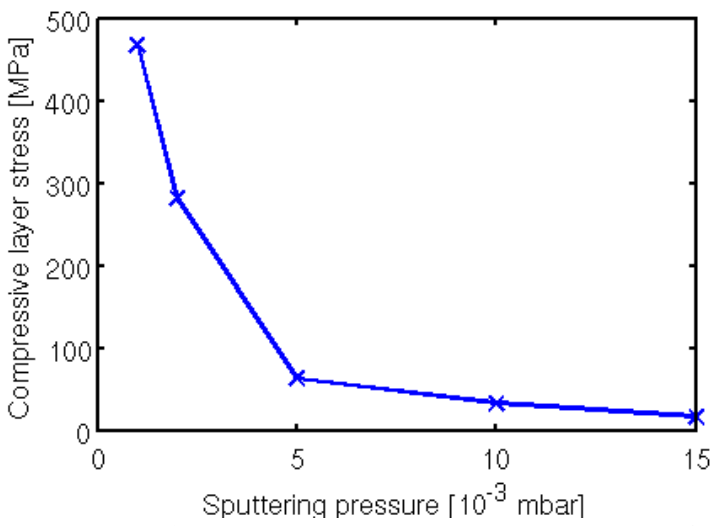

Figure 1: Measured stress in sputtered molybdenum layer as function of pressure

After covering both wafer sides with molybdenum, thick SPR220-7 is applied and patterned using the standard process. The back side of the wafer is covered first, and softbaking is done in a convection oven. A detailed process sequence is given on the right hand side of table 3.

Table 3: Process parameters of the chromium-based process used in preliminary experiments, and of the finally selected molybdenum mask based process.

\begin{tabular}{|c|c|c|}
\hline & Cr Process & Mo Process \\
\hline Cleaning & Piranha & Piranha \\
\hline $\begin{array}{l}\text { Hard mask layer, sputter } \\
\text { parameters }\end{array}$ & $\begin{array}{l}\text { Chromium, 200W 8'10-4 mbar, } \\
600 \mathrm{~nm} \text { thick (time 12' ) }\end{array}$ & $\begin{array}{l}\text { Molybdenum, } 150 \mathrm{~W} 1{ }^{\prime} 10^{-} \\
1 \text { micron thick (time } 20^{\prime} \text { ) }\end{array}$ \\
\hline Resist layer & $\begin{array}{l}\text { Resist type: } \mathrm{S} 1818 \\
\text { Spin cycle: } 1000 \mathrm{rpm}, 20 ” \\
\text { Softbake: } 90^{\circ} \mathrm{C}, 9^{\prime} \\
\text { Exposure: } 200 \mathrm{~mJ} / \mathrm{cm}^{2} \\
\text { Develop: } 2^{\prime} \text { in } 0.26 \mathrm{~N} N \mathrm{NaH} \\
\text { Hardbake: } 120^{\circ} \mathrm{C}, 2 \mathrm{~h}\end{array}$ & $\begin{array}{l}\text { Resist type: SPR220-7 } \\
\text { Spin cycle: } 2000 \mathrm{rpm}, 30 \text { ” } \\
\text { Softbake: } 115^{\circ} \mathrm{C}, 5^{\prime} \\
\text { Exposure: } 425 \mathrm{~mJ} / \mathrm{cm}^{2} \\
\text { Develop: } 5^{\prime} \text { in } 0.26 \mathrm{~N} \mathrm{NaOH}\end{array}$ \\
\hline Metal etch & $9 \%\left(\mathrm{NH}_{4}\right)_{2} \mathrm{Ce}\left(\mathrm{NO}_{3}\right)_{6}+6 \% \mathrm{HCLO}_{4}$ & $\begin{array}{l}20 \% \mathrm{H}_{2} \mathrm{O}_{2} \text { or } \mathrm{SF}_{6} \text { plasma or } \\
\text { Transene type A Al etchant }\end{array}$ \\
\hline Glass etch & $\begin{array}{l}1 \mathrm{HF}: 3 \mathrm{HNO3}: 5 \mathrm{H} 2 \mathrm{O} \text { by volume. } \\
(0.39 \mu \mathrm{m} / \mathrm{min} \text { for Pyrex } 7740)\end{array}$ & $\begin{array}{c}25 \% \mathrm{HF}, 20^{\circ} \mathrm{C} \\
(5.2 \mu \mathrm{m} / \mathrm{min} \text { for } \mathrm{D} 263 \mathrm{~m} \text { glass })\end{array}$ \\
\hline
\end{tabular}

The photoresist can serve both for the molybdenum etch as well as additional protective layer for the subsequent etching of the glass.

Glass etching was done as discussed in section 3. No nitric acid was added to the HF etchant, as this etches molybdenum rapidly [2]. Upside down turning of the wafer was relied on to remove insoluble etch products instead, as explained above.

Two tests were performed to characterize the process. In the first test, through holes are etched in the glass. In order to limit slowing down of etching because of limited supply of fresh etchant the openings in the Mo mask are taken relatively large, at least $150 \mu \mathrm{m}$. 
In this first test, etching holes throughout the $300 \mu \mathrm{m}$ thick wafers took approximately 75 minutes in 25\% HF. Images of the resulting etch front after 35 and 75 minutes can be found in figure 2. The etched planes are mirror-smooth with roughness Ra in the order or $10 \mathrm{~nm}$, measured after 35 minutes of etching.

To assess the lifetime of the mask, etching was continued to the point visible damage started to occur. This way, the mask lifetime was determined to be 3.5 hours. Consequently, the mask and glass type combination enables an etch depth of $1.25 \mathrm{~mm}$ with a single-sided etch through large mask openings without the appearance of pinholes. Pictures of an overetched through hole after 3.5 hours of etching are shown in figure 3, showing that the mask can withstand this long etch time.

In the second test, etch speed through relatively small openings and mask underetch are tested. $50 \mu \mathrm{m}$ diameter mask openings are used in order to create spherical shapes.

Several $1 \mathrm{x} 1 \mathrm{~cm}$ samples were etched in $25 \% \mathrm{HF}$ in an upside down position. After etching, the mask was stripped and the widths and depths of the etched holes were measured using an optical inspection microscope. Thus, the obtained etch depths and underetch ratios were determined. The results are summarized on the graph shown in figure 4. The error bars stand for the standard deviation, taken from measurements at minimally four positions on each sample.

It can be seen that the underetch ratio, defined as the etch depth divided by the mask underetch, is 1 within the error margin of the experiment. For the largest etch time, over 3.5 hours, it is even significantly larger. This can perhaps be explained by the difficulty to remove non dissolvable etch products from the sidewalls. In any case the mask used is shown again to be able to withstand long etches in highly concentrated HF.
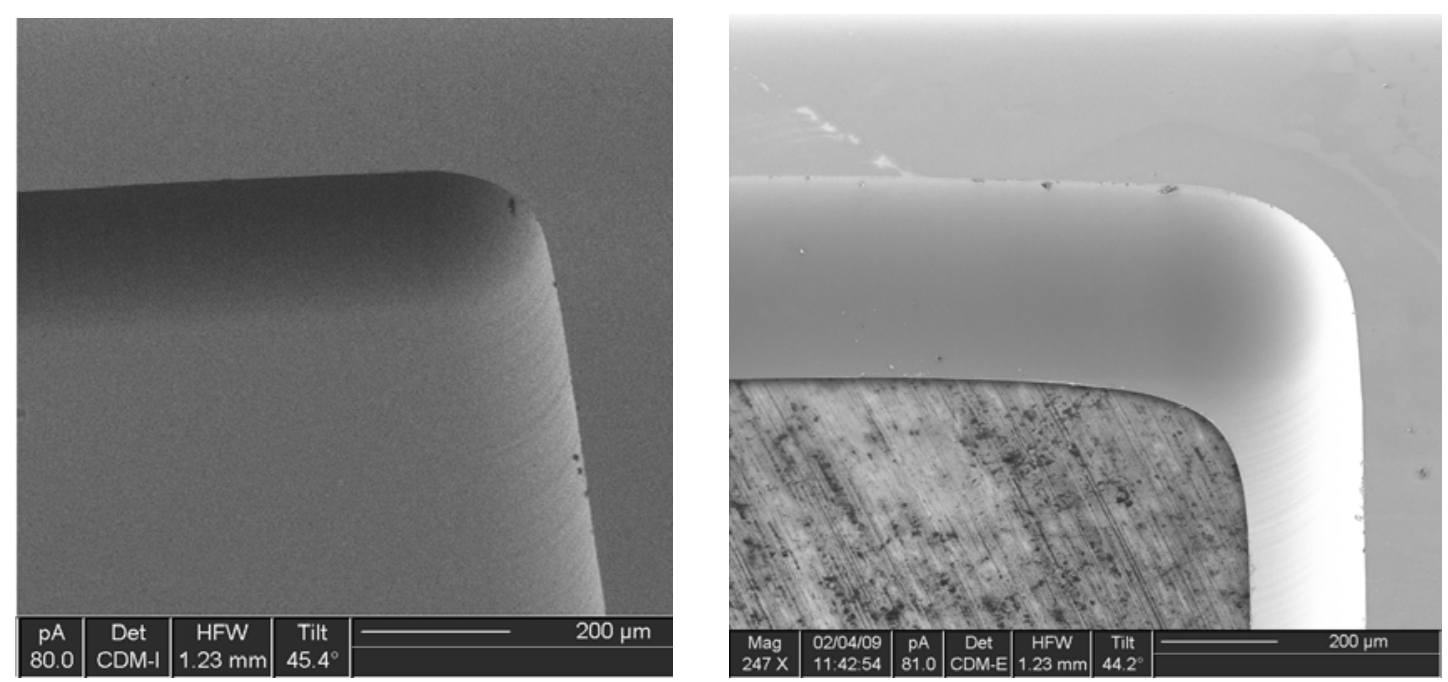

Figure 2. Etched pits after 35 (left) and 75 (right) minutes of etching, after mask removal. Etched planes are smooth, and masked parts are not damaged. 


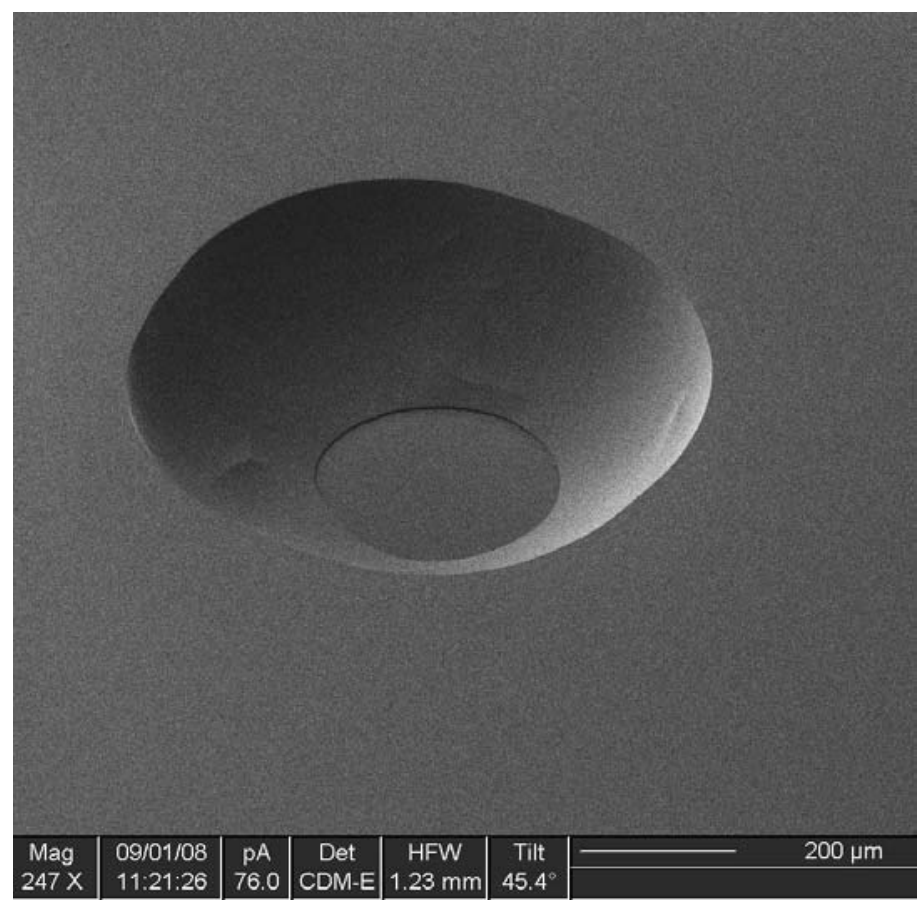

Figure 3. image of large through hole after 3.5 hours of etching, illustrating the long lifetime of the mask.

It is clear that, due to the fact fresh etchant has to diffuse though a small hole in order to etch an ever enlarging etch front, etching slows down with time. In the figure, the least square error (LSE) fit of the depth - time data with a simple square root function depth $=\mathrm{a} \cdot$ time $^{1 / 2}$ is shown as well. The constant a was determined to be $18.0 \mu \mathrm{m} \cdot \mathrm{min}^{-1 / 2}$ with a $95 \%$ confidence interval between [16.6 - 19.3]. Thus, by considering the geometry-based effect only, omitting diffusion, a reasonable first-order approximation for the etch depth versus time can be obtained.

\subsection{Discussion}

This combination of glass and etch mask yields slightly better performance than the best published processes to obtain deep wet etched glass (table 2). The process is good enough to allow the etching of quasi spherical cavities though small etch openings (figure 5). Furthermore, it is straightforward and easy to implement: sputtering tools are widely available, and molybdenum is both inexpensive and easy to etch. Molybdenum etchant is hydrogen peroxide-based and thus environmentally friendly. Moreover, the resist used as a mask for the molybdenum etching is used again during the HF etching, saving time and cost.

The D263 glass used cannot readily be used for anodic bonding to silicon as there is a substantial CTE mismatch. This is, admittingly, a disadvantage with respect to earlier results where Pyrex glass is used. However, for the fabrication of microsystems based on glass substrates only such as often done in microfluidics there is not much reason to use Pyrex. In those cases, the advantages of the method presented are clear. 


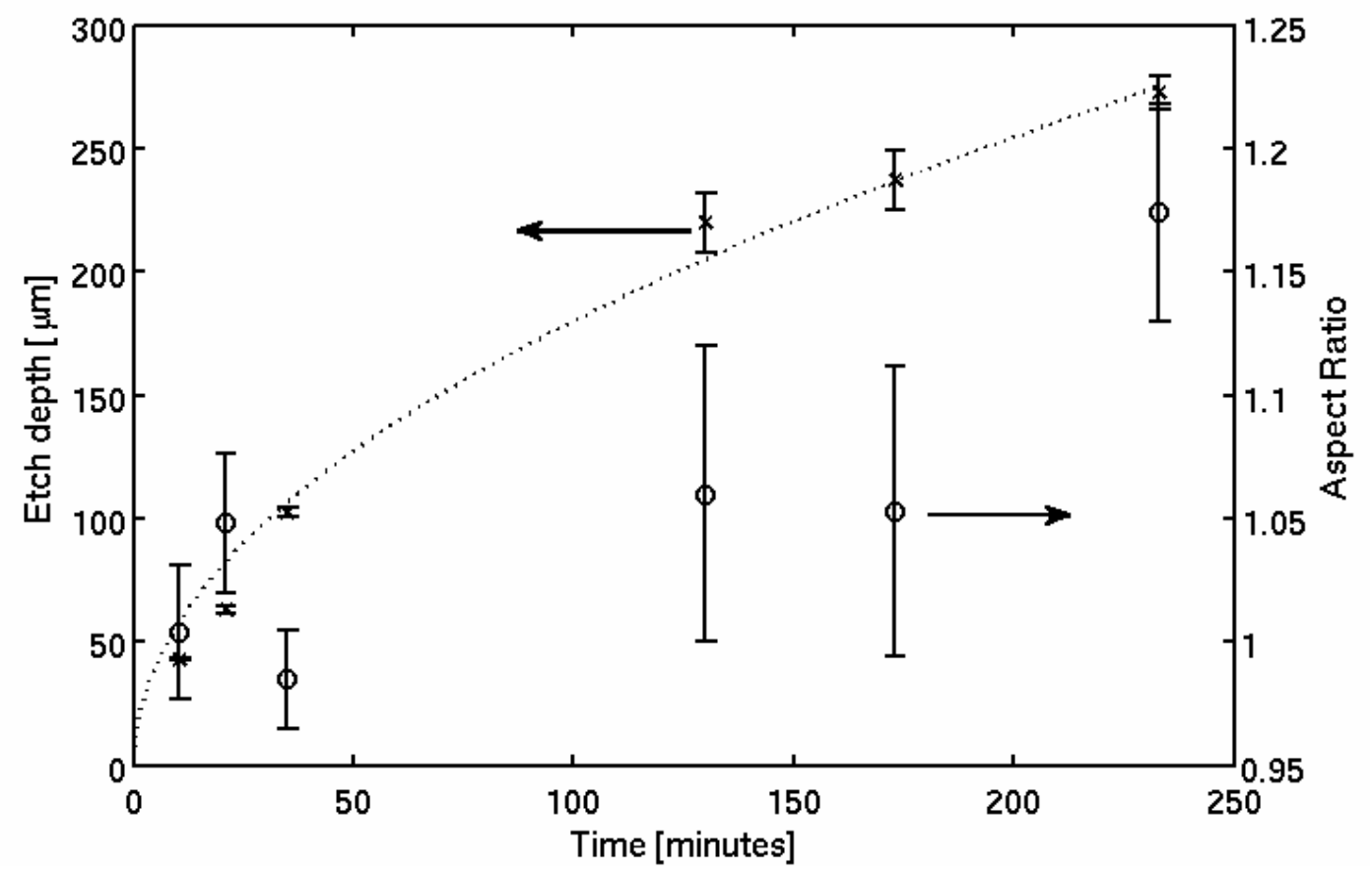

Figure 4: Etch rates and underetch ratios for etching in $25 \% \mathrm{HF}$ through narrow mask openings

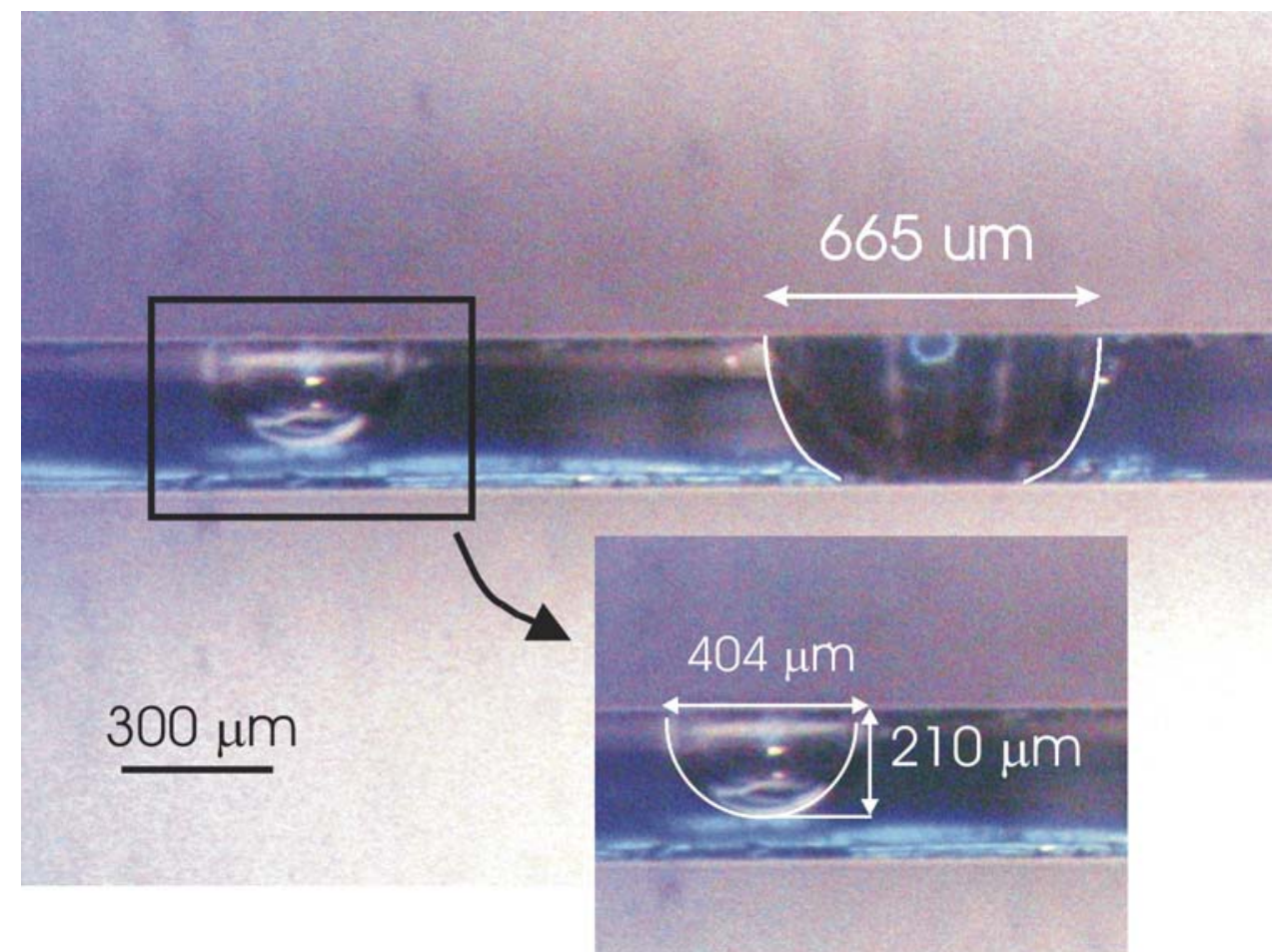

Figure 5: Sideview of etched $300 \mu \mathrm{m}$ thick D263 glass wafer. Left: hole etched through $50 \mu \mathrm{m}$ wide mask opening. Right: though hole etched though $150 \mu \mathrm{m}$ wide mask opening. 


\section{Conclusion}

A simple, low-cost process to obtain very deep isotropically etched features in glass was presented. The process uses fast etching D263 glass and a multilayer etch mask using stressoptimized molybdenum layers and positive photoresist. The mask was found to survive 3.5 hours of exposure to $25 \%$ concentrated HF solution without detachment or the appearance of pinholes. This enables deep (up to $1.2 \mathrm{~mm}$ ) wet etching of the D263 glass substrates used without underetch ratio deterioration by additional mask undercutting. Furthermore, it was observed that the wafer positioning is of significant importance in a wet glass etch process.

The process developed is a simple and affordable way to create smooth channels and vias in glass, with a performance comparable to the best processes published so far at a lower cost and complexity.

\section{Acknowledgements}

We would like to thank the Flemish government for financing this research under the GOA ZKB2156 and PowerMEMS programs. Also, thanks to Tony Van Nuland for the FIB imagery work.

\section{REFERENCES}

[1] Li X, Abe T and Esashi M 2001 Deep reactive ion etching of Pyrex glass using SF6 plasma Sensors and Actuators A 87 139-45

[2] Kirt $\mathrm{R}$ Williams 1996 Etch rates for micromachining processing Journal of Microelectromechanical Systems 5 256-269

[3] Tay F E H, Iliescu C, Jing J and Miao J 2006 Defect-free wet etching trough Pyrex glass using Cr/Au mask, Microsystem Technologies 12 935-39

[4] Stjernström M and Roeraade J 1998 Method for fabrication of microfluidic systems in glass J.Micromech. Microeng 8 33-38

[5] Iliescu C, Chen B and Miao J 2008 On the wet etching of Pyrex glass, Sensors and Actuators A 143 $154-61$

[6] Madou M J 2002 Fundamentals of Micromachining (CRC Press) p 208.

[7] Bien D C S, Rainey P V, Mitchell S N J and Gamble H S 2003 Characterization of masking materials for deep glass micromachining J.Micromech. Microeng. 13 34-40

[8] Mourzina Y, A. Steffen A and A. Offenhausser A 2005 The evaporated metal masks for chemical glass etching for BioMEMS Microsystem Technologies 11, 135-40

[9] Shoji S, Kikuchi H and Torigoe H 1998 Low-temperature anodic bonding using lithium alurninosilicate-p-quartz glass ceramic Sensors and Actuators A 64 95-100

[10] Bua M, Melvin T, Ensell G J, Wilkinson J S and Evans A G R 2004 A new masking technology for deep glass etching and its microfluidic application Sensors and Actuators A 115 476-82

[11] Steingoetter I and Fouckhardt H 2005 Deep fused silica wet etching using an Au-free and stressreduced sputter-deposited Cr hard mask J.Micromech. Microeng 15 2130-35

[12] Iliescu C, Miao J and Tay F E H 2005 Stress control in masking layers for deep wet micromachining of Pyrex glass Sensors and Actuators A. 117 286-92

[13] Grettilat M A, Paoletti F, Thiebaud P, Roth S, Kondelka-Hep M and de Rooij N F 1997 A new fabrication method for borosilicate glass capillary tubes with lateral inlets and outlets Sensors and Actuators A 60, 219-22

[14] Corman T, Enokson P and Stemme G 1998 Deep wet etching of borosilicate glass using anodically bonded silicon substrate as mask J.Micromech. Microeng 8 84-87

[15] Iliescu C, Miao J M and Tay F E H 2005 Optimization of PECVD amorphous silicon process for deep wet etching of Pyrex glass Surf. Coat. Tech. 192, 43-47

[16] Iliescu C, Chen B and Miao J 2007 Deep wet etching-through of 1mm Pyrex glass wafer for microfluidics applications: Proceedings of IEEE MEMS 2007 
[17] Steingoetter I and Fouckhardt H 2005 Deep fused silica wet etching using an Au-free and stressreduced sputter-deposited Cr hard mask J.Micromech. Microeng 15 2130-35

[18] Thornton J A and Hoffmann D W 1989 Stress related effects in thin films Thin Solid Films. 171, 5-31

[19] Harper C A 2003 Electronic Materials and Processes Handbook (NY: McGraw-Hill)

[20] Stoney G G 1909 The Tension of Metallic Films Deposited by Electrolysis Proc.R.Soc.Lond. A 82172 